\title{
Repeated Administration of Ketamine can Induce Hippocampal Neurodegeneration and Long-Term Cognitive Impairment via the ROS/HIF-1 $\alpha$ Pathway in Developing Rats
}

\author{
Jia Yan Yan Huang Yi Lu Jie Chen Hong Jiang
}

Department of Anesthesiology and Critical Care Medicine, Shanghai Ninth People's Hospital Affiliated to Shanghai Jiao Tong University School of Medicine, 639 Zhi Zao Ju Road, Shanghai 200011, China

\section{Key Words}

Anesthesia $\cdot$ Ketamine $\cdot$ Hypoxia-inducible factor- $1 \alpha \cdot$ Infant $\bullet$ Neurotoxicity $\bullet$ Apoptosis

\begin{abstract}
Background: Recent animal experiments have suggested that ketamine administration during development might induce widespread neurodegeneration and long-term cognitive deficits. The underlying mechanism is not fully understood. Methods: Immature rat hippocampal neurons and newborn rats underwent repeated exposure to ketamine, ketamine+inhibitor of hypoxia-inducible factor (HIF)- $1 \alpha(Y C-1)$, ketamine+inhibitor of reactive oxygen species(ROS) (L-carnitine) or ketamine $+\mathrm{Ca}^{2+}$ blocker(nimodipine). Apoptosis of the hippocampal neurons was analyzed by TUNEL and flow cytometry. Intracellular ROS were measured using $2^{\prime}, 7^{\prime}$-dichlorofluorescein diacetate. The expression of HIF- $1 \alpha$ and apoptosis-related proteins was analyzed by western blot or qPCR. As these rats grew, behavioral tests were performed to evaluate cognitive function. Results: The apoptotic rate in the ketamine group was significantly higher than that in the other groups, and the intracellular ROS levels in the ketamine and ketamine $+\mathrm{YC}-1$ groups were higher than those in the other groups. The expression of HIF- $1 \alpha$, p53, BNIP3 and cleaved caspase-3 proteins increased, and the ratio of $\mathrm{Bcl}-2 / \mathrm{Bax}$ decreased in the ketamine group. The transcriptional levels of HIF-1 $\alpha$ in the ketamine and ketamine+YC-1 groups were higher than those in the other groups. Cognitive deficits were found only in the ketamine group. Conclusion: We suggest that ketamine-induced neurodegeneration in neonatal rats, followed by long-term cognitive deficits, might be mediated via the ROS/HIF-1 $\alpha$ pathway.
\end{abstract}

Copyright (C) 2014 S. Karger AG, Basel 


\section{Cellular Physiology and Biochemistry}

Cell Physiol Biochem 2014;33:1715-1732

DOI: $10.1159 / 000362953$

Published onlıne: Vlay 20, 2014

C) 2014 S. Karger AG, Basel

www.karger.com/cpb

\section{Introduction}

Ketamine is a noncompetitive N-methyl-D-aspartate (NMDA) receptor antagonist widely used in pediatrics to induce general anesthesia, perioperative sedation and analgesia. The first preclinical study investigating neurotoxicity in the early stages of central nervous system (CNS) development following exposure to NMDA receptor antagonists was reported in 1999 [1]. Since then, a series of animal experiments have shown that repeated administration of ketamine can trigger neurodegeneration in the developing brain, leading to long-term defects in cognitive behavior [2-9]. The mechanism leading from ketamine uptake to neuronal cell death remains unclear. We know that blockade of NMDA receptors, by antagonists such as ketamine induces cells to activate a compensatory mechanism that causes upregulation of NMDA receptors after withdrawal of ketamine. Neurons overexpressing these receptors are more vulnerable to the excitotoxic effects of endogenous extracellular glutamate. Excessive stimulation of NMDA receptors causes the accumulation of intracellular calcium to toxic concentrations. Such an increase in calcium load, beyond the buffering capacity of the mitochondria, causes an increase in the generation of reactive oxygen species (ROS), depolarization of the mitochondrial membrane and activation of the apoptotic cascade [4, 6, 8-14]. Although neuroapoptosis might be the final outcome of an excitotoxic insult in the developing brain, the molecular pathways leading from mitochondrial dysfunction and ROS generation to apoptosis are not completely understood [11].

Recently, we described the role of hypoxia-inducible factor (HIF)-1 $\alpha$ and disrupted calcium homeostasis in neurodegeneration induced by another anesthetic, isoflurane, in the developing rat brain [15]. HIF-1 is a heterodimeric transcription factor composed of two subunits: HIF- $1 \alpha$ and HIF- $1 \beta$. The activity of HIF-1 is primarily regulated by the abundance of the HIF-1 $\alpha$ subunit, which plays a crucial role in cellular and systemic oxygen homeostasis. The general consensus regarding the role of HIF- $1 \alpha$ is that it acts as an adaptive and survival factor for cells exposed to oxygen deprivation. Under normoxic conditions, HIF- $1 \alpha$ is continuously synthesized and degraded by proteasomes, following ubiquitination and hydroxylation [16]. In contrast, under hypoxic conditions, HIF- $1 \alpha$ is stabilized and translocated to the nucleus, where it dimerizes with HIF-1 $\beta$ and activates the expression of target genes carrying hypoxia-response elements (HREs) within their promoter or enhancer elements [17]. HIF-1 thus acts as a master regulator of cellular hypoxia response, and it can directly regulate the expression of more than 70 genes in all cell types [18]. In addition to hypoxia, non-hypoxic stimuli, such as increased ROS generation, can also increase HIF-1 $\alpha$ expression under normoxic conditions [19-21]. However, under these circumstances, HIF$1 \alpha$ is known to activate a number of apoptotic genes and thus be deleterious to cells [19].

3-(5'-hydroxymethyl-2'-furyl)-1-benzyl indazole (YC-1) is an inhibitor of HIF-1 $\alpha$ that is widely used as a pharmacological tool for studying the physiological and pathological properties and functions of HIF-1 $\alpha[18,22,23]$. In this study, we used YC-1, the antioxidant L-carnitine and the $\mathrm{Ca}^{2+}$ channel blocker nimodipine to explore and dissect the involvement of calcium influx, ROS, and HIF-1 $\alpha$ in ketamine-induced neurotoxicity in the developing brains of neonatal rats.

\section{Materials and Methods}

\section{Primary culture of hippocampal neurons}

We isolated hippocampal neurons from embryonic day 18 (E18) Sprague-Dawley rat embryos. The culture medium and supplements were purchased from Life Technologies Corporation (Gibco ${ }^{\circledR}$, Shanghai, China) unless otherwise noted. The hippocampus was dissected from the brain in cold Hank's solution without $\mathrm{Mg}^{2+}$ or $\mathrm{Ca}^{2+}$ (HBSS). They were then dissociated first by trituration and then by enzymatic digestion with $0.25 \%$ trypsin, and they were finally neutralized with $10 \%$ fetal bovine serum (FBS). The neurons thus isolated were seeded onto poly-D-lysine(Sigma -Aldrich, St. Louis, MO, USA)-coated cover slips or 6-well plates (Greiner Bio-one) and were cultured in serum-free Neurobasal ${ }^{\circledR}$ medium supplemented with $2 \%$ 


\section{Cellular Physiology and Biochemistry}

Cell Physiol Biochem 2014;33:1715-1732

DOI: $10.1159 / 000362953$

Published onlıne: May 20, 2014

Yan et al.: Ketamine and HIF-1 $\alpha$ (c) 2014 S. Karger AG, Basel

www.karger.com/cpb

B27, $0.5 \mathrm{mM}$ GlutaMAX ${ }^{\mathrm{TM}}$ and penicillin-streptomycin $(100 \mathrm{U} / \mathrm{ml}-100 \mu \mathrm{g} / \mathrm{ml})$, in a humidified atmosphere $\left(5 \% \mathrm{CO}_{2}\right)$ at $37^{\circ} \mathrm{C}$. Neurons were plated at a density of $10^{6} \mathrm{cells} / \mathrm{cm}^{2}$. At $6 \mathrm{~h}$ post-seeding, the medium was replaced. On day 4, half the medium was replenished, according to previously established protocols [15, 2429]. In addition, during the first 4 days in culture, the medium was additionally supplemented with $25 \mu \mathrm{M}$ L-Glutamate (Sigma-Aldrich, St. Louis, MO, USA) as suggested by the protocol for primary rat hippocampus neurons from Life Technologies ${ }^{\mathrm{TM}}$ (http://tools.lifetechnologies.com/content/sfs/manuals/rat_cortex_and_ hippocampus_neurons.pdf).

\section{Immunostaining of hippocampal neurons}

To determine the percentage of neurons present, hippocampal neurons in culture were labeled by immunofluorescence staining, according to previous protocols [30]. Briefly, the neurons were cultured for 5 days, and the cultures were fixed with $4 \%$ paraformaldehyde for $15 \mathrm{~min}$ and were incubated with the neuron-specific primary antibody against neuron-specific enolase (NSE) (Abcam, Cambridge,UK; 1:200) overnight and finally with an appropriate fluorophore-tagged secondary antibody. The cultures were costained with 4',6-diamidino-2-phenylindole (DAPI) to label all of the nuclei. Next, the cultures were imaged under a fluorescence microscope. The neuronal percentage was determined by manually counting the number of double-stained cells per optical field and the number of cells stained with DAPI.

\section{Drug treatment (hippocampal cultures)}

On in vitro day 5 (DIV 5), the hippocampal cultures were divided into six groups according to the following treatment conditions for $3 \mathrm{~h}$ (the average terminal half life of ketamine is $186 \mathrm{~min}$ [13]), once per day for 3 consecutive days: 1) control (no treatment); 2) vehicle (dimethyl sulfoxide (DMSO); 3) $10 \mu \mathrm{M}$ ketamine (Sigma-Aldrich, St. Louis, MO, USA) as previously described [10]; 4) ketamine +100 $\mu$ M YC-1 (Cayman Chemical Company, Ann Arbor, MI, USA) dissolved in DMSO [31, 32]; 5) ketamine +30 $\mu \mathrm{M}$ antioxidant L-carnitine (Sigma, St. Louis, MO, USA) [10]; and 6) ketamine+10 $\mu \mathrm{M} \mathrm{Ca}^{2+}$ channel blocker nimodipine (Sigma, St. Louis, MO, USA) dissolved in DMSO [33, 34]. At $24 \mathrm{~h}$ after the last ketamine withdrawal from the culture media, the cells were harvested and assayed for apoptosis and gene expression. Additionally, intracellular ROS was measured at $24 \mathrm{~h}$ after the last ketamine withdrawal.

Animals

In this study, we used Sprague-Dawley (male and female) postnatal day 7 (P7) rat pups (14-18 g), provided by the Animal Center of the Shanghai Jiao Tong University School of Medicine (Shanghai, China). We obtained approval from the institutional animal care committee. The experimental protocols were in compliance with National Institutes of Health guidelines for animal experimentation. The procedures were designed to minimize the number of animals required and their suffering. All of the rats were housed at $24^{\circ} \mathrm{C}$ under a $12 \mathrm{~h} \mathrm{light} /$ dark cycle ( 7 am to $7 \mathrm{pm}$ ). The drug treatments were administered in a temperature controlled acrylic container maintained at $36.7^{\circ} \mathrm{C}$ as previously described [35].

\section{Drug treatment (animals)}

P7 rat pups were separated from their mothers for acclimatization prior to drug treatment. Each pup was randomly assigned to one of six treatment groups and was administered one intraperitoneal (i.p.) injection (10 ml/kg body weight) per day for three consecutive days, using a 30-gauge needle. The following treatment groups were established: 1) saline (control group); 2) vehicle (DMSO); 3) ketamine; 4) ketamine+YC-1; 5) ketamine+L-carnitine; 6) ketamine+nimodipine. Ketamine was diluted in saline at a concentration of $7.5 \mathrm{mg} / \mathrm{ml}$ and was administered at $75 \mathrm{mg} / \mathrm{kg}$ body weight. YC-1 was dissolved in $1 \%$ DMSO and was administered at $1 \mathrm{mg} / \mathrm{kg} 10 \mathrm{~min}$ after ketamine [18]. L-carnitine was dissolved in saline and was administered at $300 \mathrm{mg} / \mathrm{kg} 10 \mathrm{~min}$ after ketamine [36]. Nimodipine was dissolved in DMSO and was administered at $50 \mathrm{mg} / \mathrm{kg} 10 \mathrm{~min}$ after ketamine [1]. Throughout the drug treatment, the rats were provided with low-flow oxygen to avoid hypoxia. To exclude the induction of hypoxia by the administration of ketamine, 6 pups were selected from the saline and ketamine groups for arterial blood gas estimation 5 min after i.p. injection [37-39]. Twenty-four hours after the final injection, the pups were decapitated under deep anesthesia (induced by sodium pentobarbital), and their hippocampi were isolated for western blot $(n=6)$ and RT- PCR assays $(n=6)$. Brains of 6 pups of each group were also harvested $24 \mathrm{~h}$ after the final injection for TUNEL staining. Furthermore, 12 additional pups were selected from each treatment group 


\section{Cellular Physiology and Biochemistry}

Cell Physiol Biochem 2014;33:1715-1732

DOI: $10.1159 / 000362953$

Published onlıne: IVay 20, 2014

Yan et al.: Ketamine and HIF-1 $1 \alpha$

for testing of cognitive function, particularly learning and memory, once they reached a certain age. Two independent tests were used: P42 rats were subjected to the Morris water maze test and P60 rats were made to perform the passive avoidance test.

TUNEL assay (in vitro experiments)

Hippocampal cultures from all six groups were fixed and assayed for apoptotic cell death using the Fluorescent-tdT Enzyme-based FragEL ${ }^{\mathrm{TM}}$ DNA Fragmentation Detection Kit (Merck KGaA, Darmstadt, Germany). The assay was performed according to the manufacturer's instructions. Next, the cultures were imaged under a fluorescence microscope. The percentage of apoptotic cells was quantified in 12 randomly selected fields in each group.

\section{Flow cytometry and annexin V apoptotic assay}

Apoptosis was also detected using an annexin V/FITC and PI apoptosis detection kit (BectonDickinson, Franklin Lakes, NJ, USA). Briefly, primary hippocampal cultures from all six groups were planted in 6-well plates $(n=6)$ and were enzymatically dissociated into single neurons. Then, the cells were stained with annexin V-FITC and propidium iodide (PI) dye for $15 \mathrm{~min}$ in the dark at room temperature; they were then immediately analyzed by flow cytometry (FACS Calibur, Becton-Dickinson, Franklin Lakes, NJ, USA) as previously described [40].

\section{TUNEL assay (in vivo experiments)}

For TUNEL staining, the rats $(n=6)$ were first anesthetized with sodium pentobarbital and then perfused with $4 \%$ paraformaldehyde through the left cardiac ventricle and ascending aorta, $24 \mathrm{~h}$ after the final injection. Their brains were harvested and kept at $4{ }^{\circ} \mathrm{C}$ overnight in $4 \%$ paraformaldehyde solution. They were then transferred to a solution of $30 \%$ sucrose in PBS for dehydration. The samples were embedded in paraffin using standard histological procedures and were sectioned into $5 \mu$ m-thick sections $[3,41]$. Paraffin sections from all six treatment groups were subjected to a tdT enzyme- based colorimetric TUNEL assay using the FragEL ${ }^{\mathrm{TM}}$ DNA Fragmentation Detection Kit (Merck KGaA, Darmstadt, Germany). The assay was performed according to the manufacturer's instructions and previously established protocols [35]. Because the hippocampus is involved in learning and memory, and the CA1 and dentate gyrus (DG) regions are more susceptible to anesthetic-induced apoptosis, compared to other regions of the hippocampus [2, 3 , 37], we quantified the number of apoptotic neurons in randomly selected sections (one slide per animal), within two fields of each CA1 and DG region. A total of 12 fields in each region in each treatment group were analyzed under a light microscope in a double blinded-manner.

\section{ROS Measurement}

The concentration of ROS was determined by fluorometric assay using 2',7'-dichlorofluorescein diacetate (DCFH-DA, Molecular Probes, Eugene, OR, USA). Briefly, primary hippocampal cultures $(n=6)$ from all six groups were incubated with $10 \mu \mathrm{M}$ DCFH-DA for $30 \mathrm{~min}$ and then were washed twice with ice-cold PBS, $24 \mathrm{~h}$ after drug treatment in each group. The fluorescence intensity was quantified at $485 \mathrm{~nm}$ excitation and $530 \mathrm{~nm}$ emission using a live cell imaging system (Olympus LCS SYSTEM, Japan).

\section{Western Blot}

For the in vitro experiments, hippocampal culture samples were collected from six dishes per treatment group. For the in vivo experiments, hippocampal tissue samples were collected from six P7 animals per treatment group. The samples were rinsed twice with ice-old PBS and were lysed in cold RIPA Lysis Buffer (Beyotime, Beijing, China) for $30 \mathrm{~min}$. The lysates were centrifuged at 12,000 g for $20 \mathrm{~min}$ at $4^{\circ} \mathrm{C}$, and their protein concentrations were determined using the BCA Protein Assay Kit (Beyotime, Beijing, China). Total protein $(30 \mu \mathrm{g})$ was mixed with $1 \times$ loading buffer, boiled for $5 \mathrm{~min}$, and then separated by $10 \%$ polyacrylamide gel electrophoresis. The protein bands were transferred to a nitrocellulose membrane (Invitrogen, Shanghai, China), which was first blocked in 10\% nonfat dried milk in TBST for $2 \mathrm{~h}$ and then probed overnight with the following primary antibodies: anti-HIF-1 $\alpha$ (1:500), anti- cleaved caspase-3 (1:1000), anti-p53 (1:100), anti-BNIP3 (1:500), anti-Bcl-2(1:200), anti-Bax (1:100), and anti- $\beta$-actin (1:500, internal loading control) (Santa Cruz, CA, USA) at $4{ }^{\circ} \mathrm{C}$. The following day, the membranes were washed with TBST and incubated in goat anti-rabbit HRP-conjugated IgG (Santa Cruz, CA, USA) at 1:5000 dilution for $2 \mathrm{~h}$. 


\section{Cellular Physiology and Biochemistry}

Cell Physiol Biochem 2014;33:1715-1732

\begin{tabular}{l|l}
\hline DOI: $10.1159 / 000362953$ & (C) 2014 S. Karger AG, Basel
\end{tabular}

The blots were developed using the ECL kit (Pierce, Rockford, IL, USA) and were quantified using Quantity One software.

\section{Real-time PCR}

For the in vitro experiments, hippocampal culture samples were collected from six dishes per treatment group. For the in vivo experiments, hippocampal tissue samples were collected from six P7 animals per treatment group. Each sample was analyzed three times. Total RNA was extracted with Trizol (Invitrogen, Shanghai, China) according to the manufacturer's instructions. cDNA was prepared from $2 \mu \mathrm{g}$ of total RNA using a SuperScript II RT kit (Invitrogen, Carlsbad, CA, USA). Real-time quantitative PCR was performed with SYBR Green PCR Master Mix on an ABI 7500 Real-Time PCR System (Applied Biosystems, Foster City, CA, USA). Relative mRNA expression was calculated by normalizing to $\beta$-actin. The data were analyzed using the $2^{-\Delta \Delta C t}$ method. The following primers were used:

HIF-1 $\alpha$ (NM: 024359.1),

forward: 5' -TAC AAG AAA CCG CCT ATG AC-3'

reverse: 5' -CAT AAC CCA TCA ACT CAG TAA TC-3'; and

$\beta$-actin (NM: 031144.3),

forward: 5' -CCT CTA TGC CAA CAC AGT-3'

reverse: 5' -AGC CAC CAA TCC ACA CAG-3'.

\section{Behavioral Tests}

Two independent tests were performed: P42 rats were subjected to the Morris water maze test and P60 rats were made to perform the passive avoidance test.

The apparatus used for the Morris water maze test (Chengdu Instrument Ltd., Sichuang, China. Software: MS-type Water Maze Video analysis system, version 2.5) included a black circular pool with the following dimensions: $160 \mathrm{~cm}$ in diameter and $60 \mathrm{~cm}$ in height. A platform of $10 \mathrm{~cm}$ in diameter was placed at a random location in the pool and was submerged $2 \mathrm{~cm}$ below the water surface. The water temperature was set at $23^{\circ} \mathrm{C}$. Trials were conducted twice per day for five consecutive days. During each trial, the rats were released into the water from a specific starting point located at the quadrant opposite the platform. The latency in finding the platform and the distance swum before reaching the platform were recorded, and the rat was allowed to remain upon the platform for $30 \mathrm{~s}$ (orientation period). If a rat did not find the platform within $120 \mathrm{~s}$, the rat was gently guided to the platform and was allowed to stay on it for $30 \mathrm{~s}$, and the latency was recorded as $120 \mathrm{~s}$. At the end of the five training days, the platform was removed, and the rats were released into the water from the same starting point and were allowed to swim freely for $120 \mathrm{~s}$. We recorded the number of times the platform was crossed by the rat and the proportion of time spent in the range around the platform, as set in the software.

The passive avoidance test was performed according to previously established protocols [42]. Briefly, animals habituated in the dark were placed in a lighted compartment and were allowed to re-enter the dark compartment. Subsequently, an electric foot shock was delivered to the animals that entered the dark compartment (learning exercise). In the assays conducted $24 \mathrm{~h}$ later, the time taken by the animal to reenter the dark compartment (latency) was recorded. If a rat did not re-enter the dark compartment within $180 \mathrm{~s}$, the latency was recorded as $180 \mathrm{~s}$.

\section{Statistical analysis}

All of the data are expressed as the means \pm SEMs. One-way ANOVA was performed to determine statistically significant differences among the treatment groups, using GraphPad Prism Software (Prism 5 for Windows, GraphPad Software Inc., San Diego, CA, USA). Post-hoc individual means comparisons were conducted by Tukey's multiple comparisons tests. Significance was set at $P$ values less than 0.05 .

\section{Results}

Ketamine-induced apoptosis of immature hippocampal neurons could be rescued by YC-1, L-carnitine and nimodipine in vitro

We first prepared primary hippocampal cultures from E18 embryos and examined these cultures at DIV 5 under a brightfield microscope, to examine their morphology (Fig. 1A) 


\section{Cellular Physiology and Biochemistry}

Cell Physiol Biochem 2014;33:1715-1732
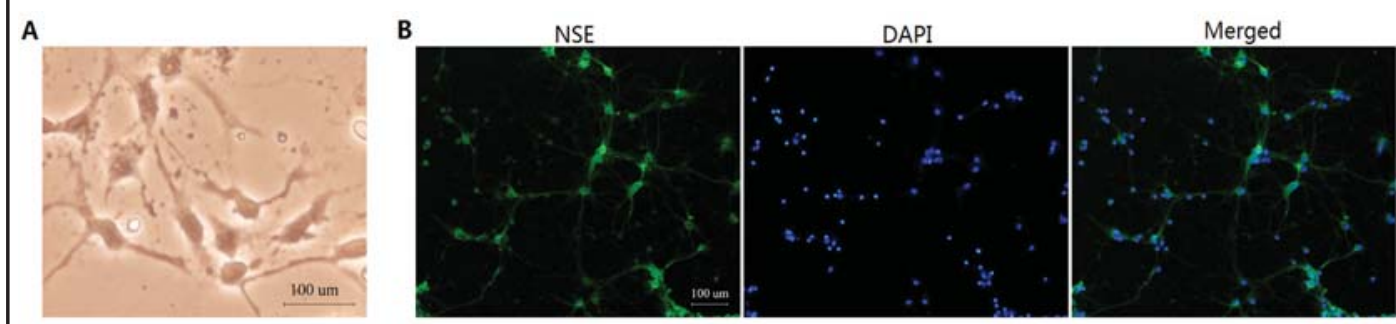

Fig. 1. Histological identification of hippocampal neurons in vitro. (A) Brightfield images at DIV 5 show cells with the morphological appearance of neurons, with dense, thick and long neurites. (B) Immunofluorescent staining of hippocampal neurons against NSE (green); all cultured cells counterstained with DAPI (blue); also shown is a merged image of the two stainings. Scale bar $=100 \mu \mathrm{m}$.

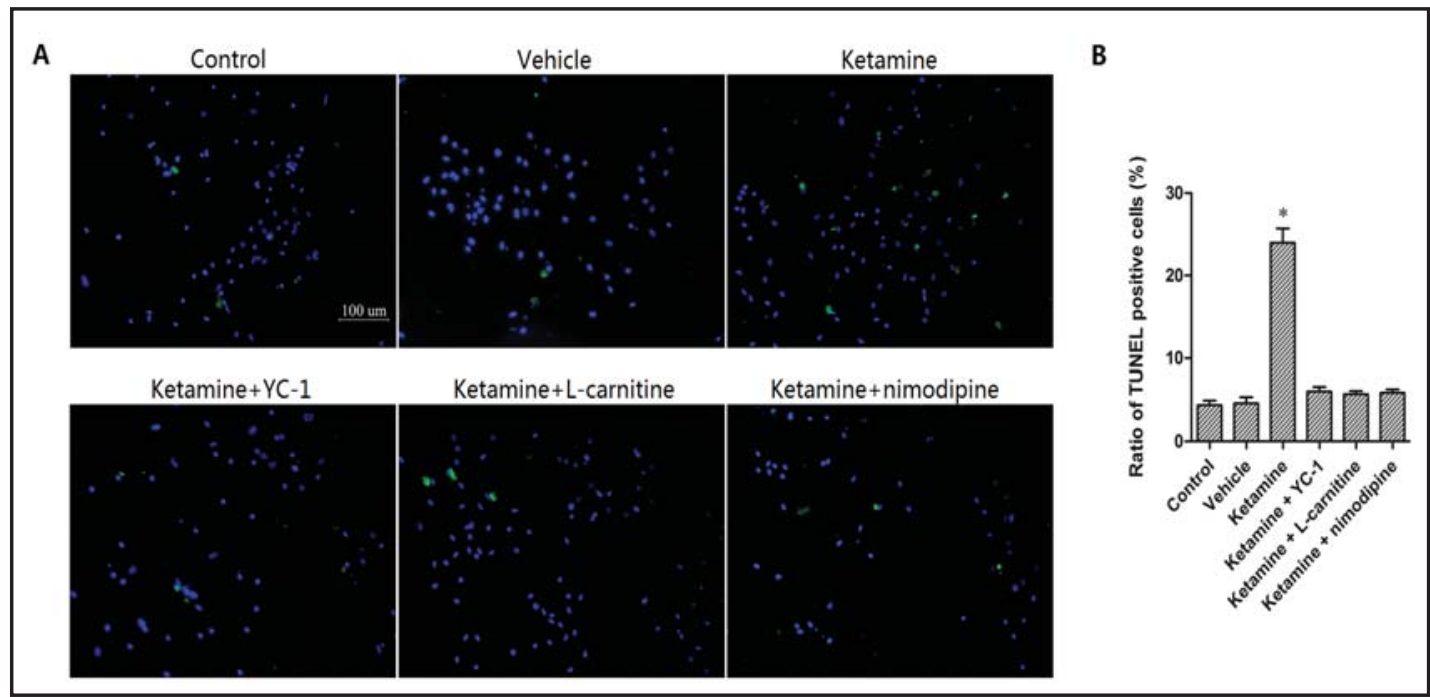

Fig. 2. TUNEL-based assay for apoptosis of hippocampal neurons in vitro. Hippocampal cultures were divided into six groups according to the different treatment conditions (control, vehicle, ketamine+YC-1, ketamine+L-carnitine and ketamine+ nimodipine) for $3 \mathrm{~h}$, once per day for 3 consecutive days. The cells were fixed and assayed for apoptotic cell death at $24 \mathrm{~h}$ after the last ketamine withdrawal from the culture media. (A) Representative merged fluorescent images of neurons co-stained with TUNEL (green) and DAPI (blue). (B) Quantification of the percentage of TUNEL-positive apoptotic cells over the total number of cells $(F[5,66]=79.24, P<0.0001)$ in each treatment group. Scale bar $=100 \mu \mathrm{m}$. ${ }^{*} P<0.05$ versus any of the other groups.

The neurons appeared healthy, with successfully extended, thick, dense and long neurites. To determine the percentage of neurons in culture, we performed immunofluorescence staining for the pan-neuronal marker NSE, which stained the cytoplasm and neurites of the neurons and counterstained all of the cells with the nuclear dye DAPI (Fig. 1B). From merged images of the two stainings, we quantified the percentage of NSE+ neurons among all of the cells in culture (DAPI+). We found that more than $90 \%$ cells in culture were neurons (Fig. 1B; data not shown).

To study the effects of repeated ketamine exposure on immature hippocampal neurons, we assayed for neuronal cell death under the different treatment conditions. Fixed hippocampal cultures were stained for fragmented DNA, a characteristic of apoptosis, using the TUNEL assay (Fig. 2A). Cultures from all six groups were TUNEL-stained (green), and stained for DAPI (blue). Next, we quantified the percentage of cells that were TUNEL-positive 


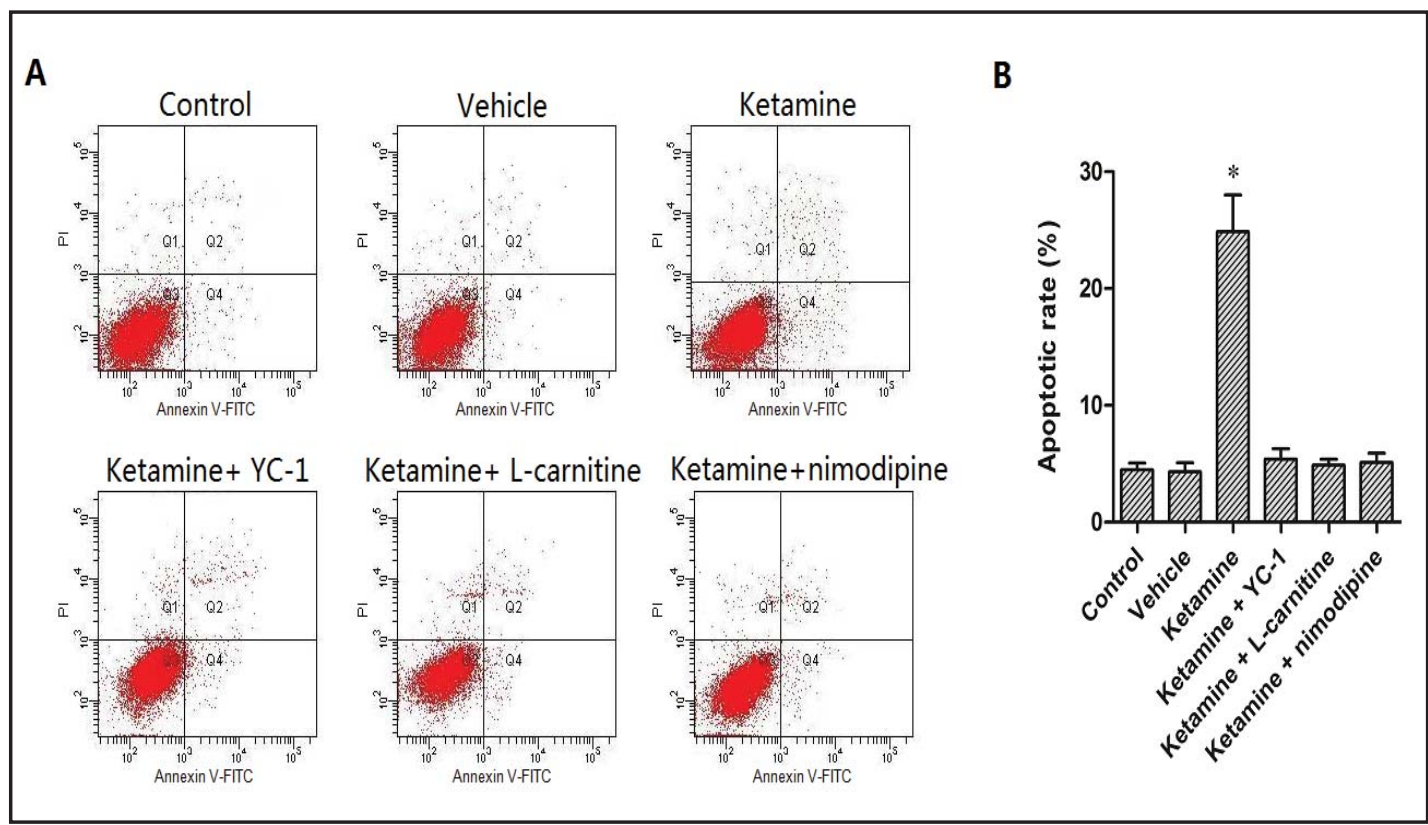

Fig. 3. Annexin V-based FACS assay for apoptosis of hippocampal neurons in vitro. Hippocampal cultures were divided into six groups according to the different treatment conditions (control, vehicle, ketamine+YC-1, ketamine+L-carnitine and ketamine+nimodipine) for $3 \mathrm{~h}$, once per day for 3 consecutive days. Cells were stained with annexin V-FITC and PI and were assayed for apoptosis at $24 \mathrm{~h}$ after the last ketamine withdrawal from the culture media. (A) Flow cytometric sorting of apoptotic cells in primary cultures of hippocampal neurons by labeling with fluorescent conjugates of annexin V (quadrants 2 and 4). (B) Quantification of the percentage of apoptotic cells in six treatment groups $(F[5,30]=32.31, P<0.0001) .{ }^{*} P<0.05$ versus any of the other groups.

(Fig. 2B). We found that when exposed to repeated doses of ketamine, approximately $25 \%$ of cells underwent apoptotic cell death, which was significantly greater than in the control and vehicle-treated groups, in which only $5 \%$ of cells were TUNEL-positive. Interestingly, when the cultures were treated with any of the neuroprotective factors-YC-1, L-carnitine, or nimodipine-the increase in TUNEL staining was prevented and the percentage of cell death was restored to control levels.

To determine the level of apoptosis comprehensively and in a larger population of primary hippocampal neurons, we performed flow cytometric analysis. We dissociated hippocampal cultures from all six groups into single neurons, stained them with fluorophoreconjugated annexin $V$ and FACS and sorted them into apoptotic and non-apoptotic populations (Fig. 3A). As shown, those cells stained strongly by annexin $\mathrm{V}$ conjugates were labeled and quantified as apoptotic cells (quadrants 2 and 4). Similar to our results from TUNEL staining, we found that approximately $25 \%$ of the total cells were apoptotic in the ketamine group, which was significantly higher than in the control and vehicle groups (approximately 5\%). Again, when treated with either YC-1, L-carnitine or nimodipine, the percentage of apoptosis was rescued and restored to control levels (Fig. 3B).

Ketamine-induced apoptosis of hippocampal neurons in the developing rat brain could be prevented by $Y C-1, L$-carnitine and nimodipine

To corroborate our findings on the effects of ketamine exposure on primary hippocampal neurons in vitro, we determined whether ketamine had the same effects during development in vivo. We first performed arterial blood gas analysis on samples collected from the saline and ketamine groups, to ensure that the ketamine used in our study did not have a depressive 
Table 1. Arterial blood gas analysis for saline group and ketamine group $(n=6)$. ${ }^{*} P<0.05$ compared with saline group

\begin{tabular}{lcccccc}
\hline & $\mathrm{PH}$ & $\mathrm{pCO}_{2}$ & $\mathrm{pO}_{2}$ & $\mathrm{sO}_{2}$ & $\mathrm{Lac}$ & $\mathrm{HCO}_{3}{ }^{-}$ \\
\hline Saline & $7.449 \pm 0.020$ & $26.4 \pm 2.2$ & $142.8 \pm 7.3$ & $99.5 \pm 0.1$ & $1.7 \pm 0.2$ & $20.6 \pm 0.3$ \\
Ketamine & $7.444 \pm 0.018$ & $29.3 \pm 1.7$ & $124.4 \pm 8.6$ & $99.3 \pm 0.3$ & $2.0 \pm 0.4$ & $22.1 \pm 0.6$ \\
\hline
\end{tabular}

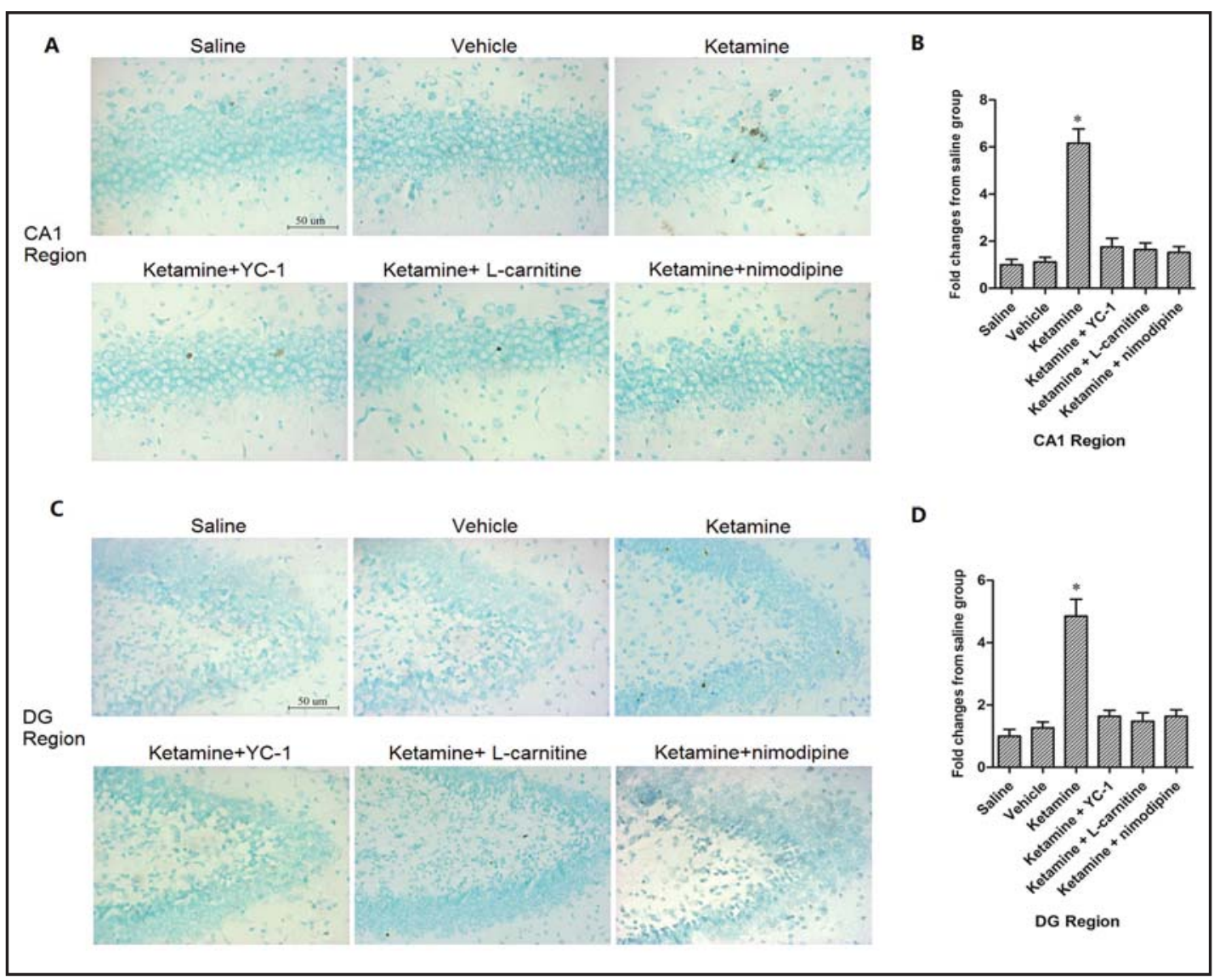

Fig. 4. TUNEL-based assay for apoptosis of hippocampal neurons in vivo. P7 rat pups were divided into six groups according to different drug treatments (saline, vehicle, ketamine, ketamine+YC-1, ketamine+L-carnitine, ketamine+nimodipine) by i.p. injection, once per day for 3 consecutive days. Brains of each group were harvested $24 \mathrm{~h}$ after the final injection for TUNEL staining. (A) Representative images of the hippocampal CA1 region, stained for TUNEL-positive apoptotic nuclei (brown) in the six treatment groups. (B) Quantification of TUNEL-positive cells in the hippocampal CA1 region $(F[5,66]=31.83, P<0.0001)$. (C) Representative images of the hippocampal DG region, stained for TUNEL-positive apoptotic nuclei (brown) in the six treatment groups. (D) Quantification of TUNEL-positive cells in the hippocampal DG region $(F[5,66]=28.76$, $P<0.0001)$. Data are represented as fold changes relative to the saline group. Scale bar $=50 \mu \mathrm{m} .{ }^{*} P<0.05$ versus any of the other groups.

respiratory effect, which could cause hypoxic brain injury. As shown in Table 1, we found no significant differences in acidity $(\mathrm{pH})$, concentration of plasma-dissolved $\mathrm{CO}_{2}\left(\mathrm{pCO}_{2}\right)$ and $\mathrm{O}_{2}$ $\left(\mathrm{pO}_{2}\right)$, oxyhemoglobin saturation $\left(\mathrm{sO}_{2}\right)$, or level of $\mathrm{HCO}_{3}{ }^{-}$, which is indicative of metabolic distress, between the two groups.

To determine the level of apoptosis, we performed TUNEL assay on paraffinized sections of brains collected from all six treatment groups, specifically in two regions of the hippocampus: CA1 and DG (Fig. 4A \& C). Next, we quantified the number of TUNEL-positive apoptotic nuclei (brown) within the selected regions, and we found a significant increase in 


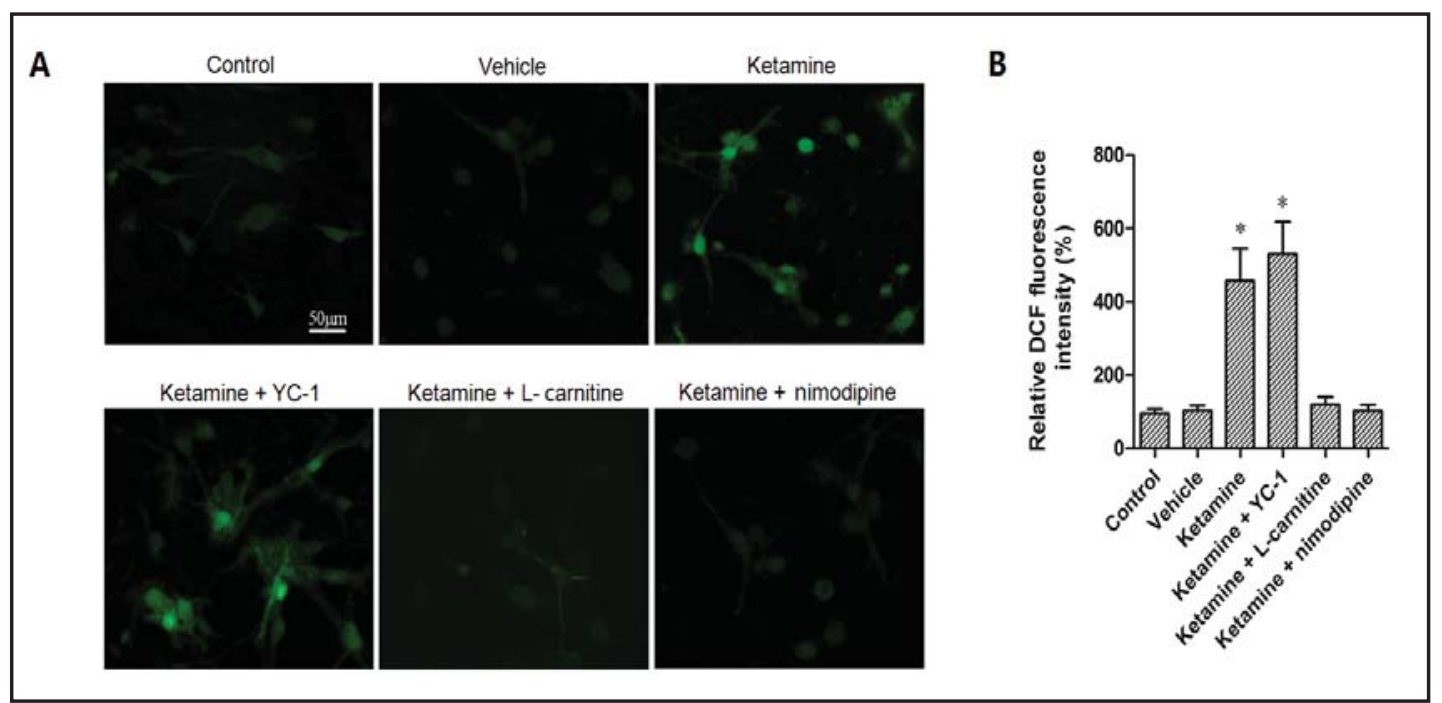

Fig. 5. Measurement of ROS levels in hippocampal neurons in vitro, using DCFH-DA. Hippocampal cultures were divided into six groups according to the different treatment conditions (control, vehicle, ketamine+YC-1, ketamine+L-carnitine and ketamine+nimodipine) for $3 \mathrm{~h}$, once per day for 3 consecutive days. Cells were assayed for level of intracellular ROS at $24 \mathrm{~h}$ after the last ketamine withdrawal from the culture media. (A) ROS levels in cultures from all six treatment groups were assessed by DCF fluorescence. (B) The relative changes in ROS generation were determined by measuring the intensity of the DCF fluorescence signal $(F[5,30]=14.81, P<0.0001)$. Data are presented as fluorescence intensity relative to the control group. Scale bar=50 $\mu \mathrm{m} .{ }^{*} P<0.05$ versus each of the four groups (control, vehicle, ketamine $+\mathrm{L}-$ carnitine, ketamine+nimodipine).

the ketamine group, compared to the saline-treated control group $(P<0.05)$ (Fig. 4B \& D). No differences were seen in the vehicle-treated animals. Interestingly, in the brains collected from animals treated with the neuroprotective factors YC-1, L-carnitine or nimodipine following ketamine exposure, the increase in apoptosis was prevented, and the number of TUNEL-positive nuclei was restored to control levels (Fig. 4B \& D).

\section{Ketamine increased the generation of ROS in primary hippocampal neurons}

NMDA receptor antagonism can lead to increased calcium influx, which can result in increased production of ROS. Hence, to dissect the signaling mechanisms leading from ketamine exposure to apoptosis in vitro, we next examined the generation of ROS in hippocampal cultures by staining them with DCFH-DA, a non-fluorescent molecule that can diffuse into cells and be oxidized by cellular ROS into the fluorescent $2^{\prime}, 7^{\prime}$-dichlorofluorescein (DCF). Hippocampal cultures from all six groups were thus analyzed (Fig. 5). We found that repeated exposure to ketamine significantly enhanced the generation of ROS, as indicated by increased DCF fluorescence intensity. While treatment of cells with L-carnitine and nimodipine rescued this effect and restored ROS concentrations to control levels, the HIF$1 \alpha$ inhibitor YC-1 had no effect on the intensity of DCF fluorescence, suggesting that HIF-1 $\alpha$ acted downstream of ROS upregulation.

Ketamine exposure in vitro caused upregulation of HIF-1 $\alpha$ and pro-apoptotic factors, which were rescued by $Y C-1, L$-carnitine and nimodipine

It is known that excessive cellular ROS can induce expression of HIF-1 $\alpha$, which can in turn activate several downstream pro-apoptotic genes to facilitate cell death [21, 43-45]. To determine whether ketamine-induced upregulation of ROS in primary hippocampal neurons could have a similar effect, we next assayed the expression level of HIF-1 $\alpha$, the pro-apoptotic proteins p53, BNIP3 and Bax, the anti-apoptotic/pro-survival protein Bcl-2, and cleaved caspase-3, the enzyme mediating apoptotic cell death, by western blotting (Fig. 6A). The 


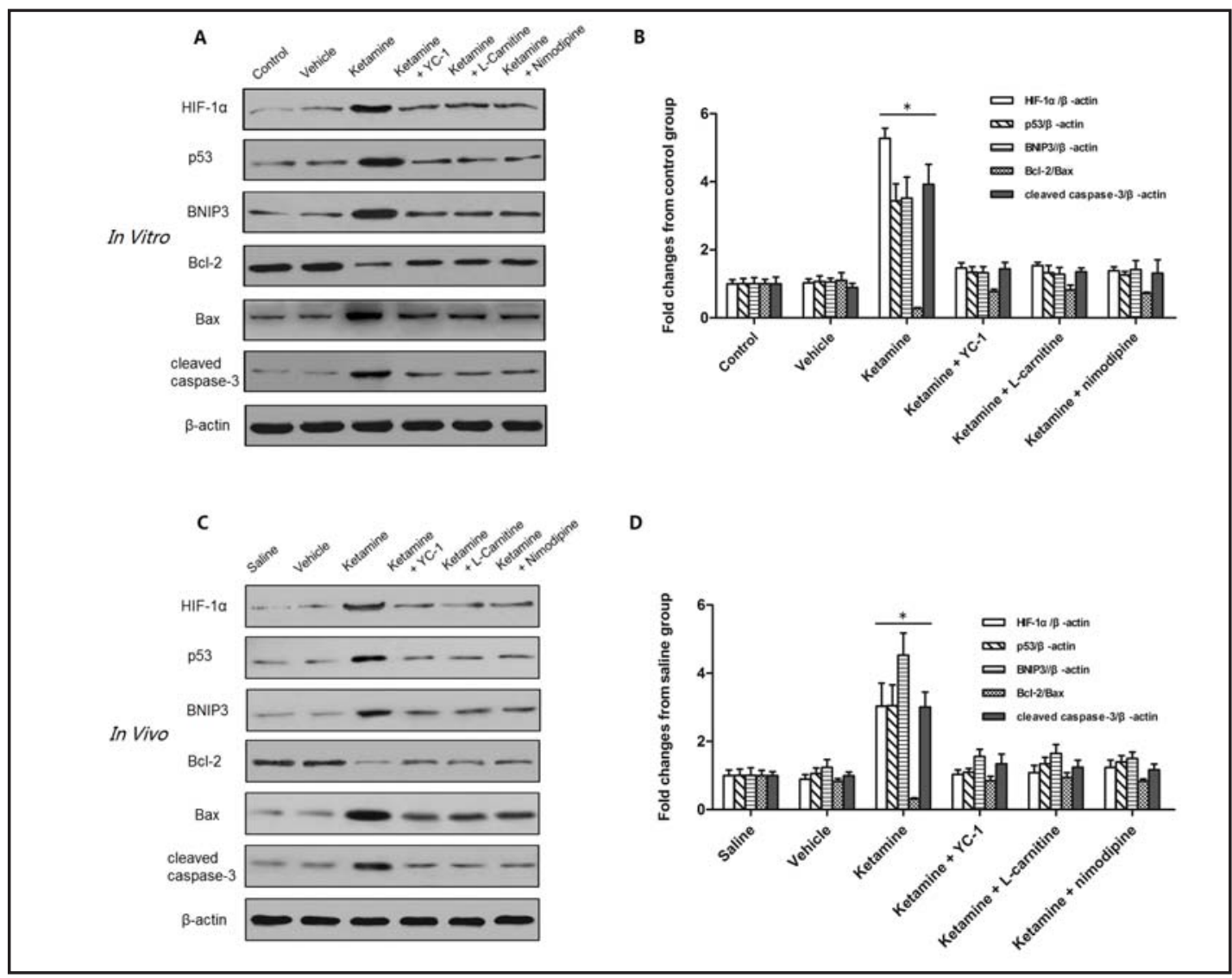

Fig. 6. Western blot analysis of HIF-1 $\alpha$, the pro-apoptotic proteins p53, BNIP3 and Bax, the anti-apoptotic protein $\mathrm{Bcl}-2$, and the apoptotic enzyme cleaved caspase- 3 in vitro and in vivo. For the in vitro experiments, hippocampal cultures were divided into six groups according to the different treatment conditions (control, vehicle, ketamine+YC-1, ketamine+L-carnitine and ketamine+nimodipine) for $3 \mathrm{~h}$, once per day for 3 consecutive days. Cells were harvested at $24 \mathrm{~h}$ after ketamine withdrawal from the culture media. For the in vivo experiments, $\mathrm{P} 7$ rat pups were divided into six groups according to different drug treatments (saline, vehicle, ketamine, ketamine+YC-1, ketamine+L-carnitine, ketamine+nimodipine) by i.p. injection, once per day for 3 consecutive days. Hippocampal tissue samples were collected from each group at $24 \mathrm{~h}$ after the final injection. (A) Representative blots showing bands corresponding to all of the assayed proteins in vitro, under each of the six treatment conditions. $\beta$-actin was used as the internal control. (B) Quantification of the assayed protein expression levels based on optical density measurement in vitro (HIF- $1 \alpha / \beta$-actin: $\mathrm{F}[5,30]=10.41, P<0.0001 ; \mathrm{p} 53 / \beta$-actin: $\mathrm{F}[5,30]=13.15, P<0.0001 ;$ BNIP3/ $\beta$-actin: $\mathrm{F}[5,30]=9.55, P<0.0001$; Bcl-2/Bax: $F[5,30]=5.04, P=0.0018$; cleaved caspase-3/ $\beta$-actin: $F[5,30]=12.74, P<0.0001$ ). (C) Representative blots showing bands corresponding to all of the assayed proteins in vivo, under each of the six treatment groups. $\beta$-actin was used as the internal control. (D) Quantification of protein expression levels based on optical density measurement in vivo (HIF- $\alpha / \beta$-actin: $\mathrm{F}[5,30]=6.51, P=0.0003 ; \mathrm{p} 53 / \beta$-actin: $\mathrm{F}[5,30]=7.17$, $P=0.0002$; BNIP3/ $\beta$-actin: $F[5,30]=15.08, P<0.0001$; Bcl-2/Bax: $F[5,30]=5.08, P=0.0017$; caspase- $3 / \beta$-actin: $\mathrm{F}[5,30]=9.57, P<0.0001)$ Data are represented as fold changes from the ratio of the target protein $/ \beta$-actin or Bcl-2/Bax density relative to the control (in vitro) or saline (in vivo)group. ${ }^{*} P<0.05$ versus any of the other groups.

optical density of the protein bands thus separated was quantified and compared among the six treatment groups (Fig. 6B). We found significantly increased expression of HIF-1 $\alpha$, p53, BNIP3, and cleaved caspase-3 in the ketamine group, compared with the control and vehicletreated cells (Fig. 6B). As a corollary, we also found a significant decrease in the expression of Bcl-2/Bax ratio in the ketamine group (Fig. 6B). As anticipated from the results of the TUNEL and annexin $V$ assays, when cultured neurons were co-treated with YC-1, L-carnitine 
A

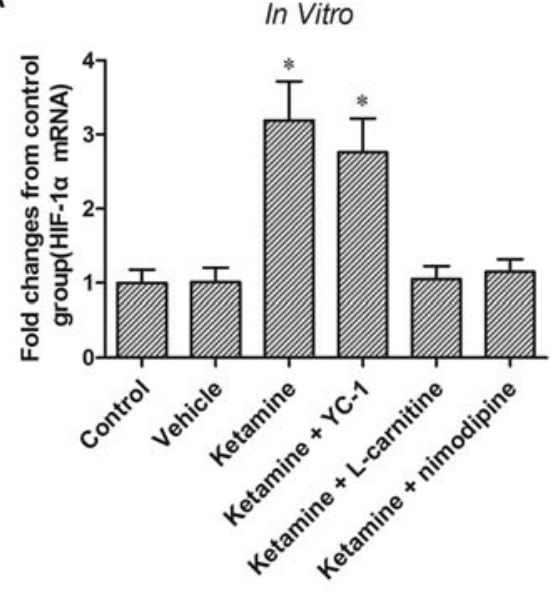

B

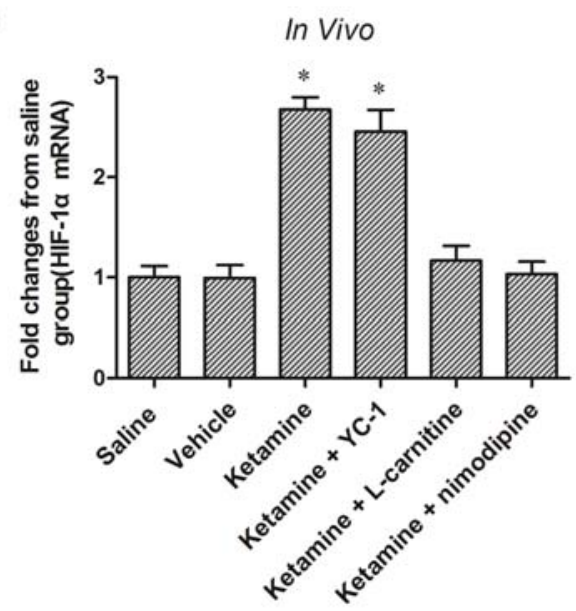

Fig. 7. Effects of ketamine, YC-1, L-carnitine and nimodipine on HIF-1 $\alpha$ mRNA expression. Relative mRNA expression was calculated by normalizing to $\beta$-actin. Quantification of mRNA levels of HIF-1 $\alpha$ from RT- PCR assays are represented as fold changes relative to the control/saline group. (A) In vitro (F[5,30] $=9.85$, $P<0.0001)$. Hippocampal cultures were divided into six groups according to the different treatment conditions (control, vehicle, ketamine+YC-1, ketamine+L-carnitine and ketamine+nimodipine) for $3 \mathrm{~h}$, once per day for 3 consecutive days. Cells were harvested at $24 \mathrm{~h}$ after the last ketamine withdrawal from the culture media. (B) In vivo (F[5,30]=29.33, $P<0.0001)$. P7 rat pups were divided into six groups according to different drug treatments (saline, vehicle, ketamine, ketamine+YC-1, ketamine+L-carnitine, ketamine+nimodipine) by i.p. injection, once per day for 3 consecutive days. Hippocampal tissue samples were collected from each group at $24 \mathrm{~h}$ after the final injection. ${ }^{*} P<0.05$ versus each of the four groups (control/saline, vehicle, ketamine+L-carnitine, ketamine+nimodipine).

or nimodipine, the upregulation of pro-apoptotic factors was rescued and restored to control levels (Fig. 6B). Similarly, the ratio of Bcl-2/Bax was increased to control levels (Fig. $6 \mathrm{~B})$. These findings suggest that ketamine could activate apoptotic signaling pathways in hippocampal neurons by causing an increase in HIF-1 $\alpha$ expression.

Ketamine exposure in vivo caused upregulation of HIF-1 $\alpha$ and pro-apoptotic factors, which was rescued by $Y C-1, L$-carnitine and nimodipine

To corroborate the above findings in the developing rat brain in vivo, we next analyzed hippocampal protein extracts from the six treatment groups by western blotting (Fig. 6C). Similar to the in vitro experiment, we found significant upregulation of HIF-1 $\alpha$, p53, BNIP3, and cleaved caspase-3 in the ketamine group, compared with the saline-and vehicletreated groups (Fig. 6D). Additionally, as a corollary, the ratio of Bcl-2/Bax was significantly downregulated in the ketamine group (Fig. 6D). Finally, in samples collected from animals that were administered YC-1, L-carnitine or nimodipine following ketamine exposure, the enhanced apoptotic state was prevented, and the levels of HIF- $1 \alpha$, pro-apoptotic factors, and cleaved caspase- 3 and the ratio of Bcl-2/Bax were not significantly different from those in the control group (Fig. 6D). Hence, our observations on the relationships among ketamine exposure, HIF-1 $\alpha$ expression and activation of pro-apoptotic pathways in vitro and in vivo were concordant.

L-carnitine and nimodipine, but not YC-1, downregulated HIF-1 $\alpha$ mRNA levels in ketamineexposed immature hippocampal neurons

The above results suggest that YC-1, L-carnitine and nimodipine, although belonging to different functional classes of small molecules and neuroprotective factors, all contributed to downregulation of elevated levels of HIF-1 $\alpha$ protein in ketamine-exposed neurons, as seen from western blot assay. We further confirmed this regulatory effect by quantifying 


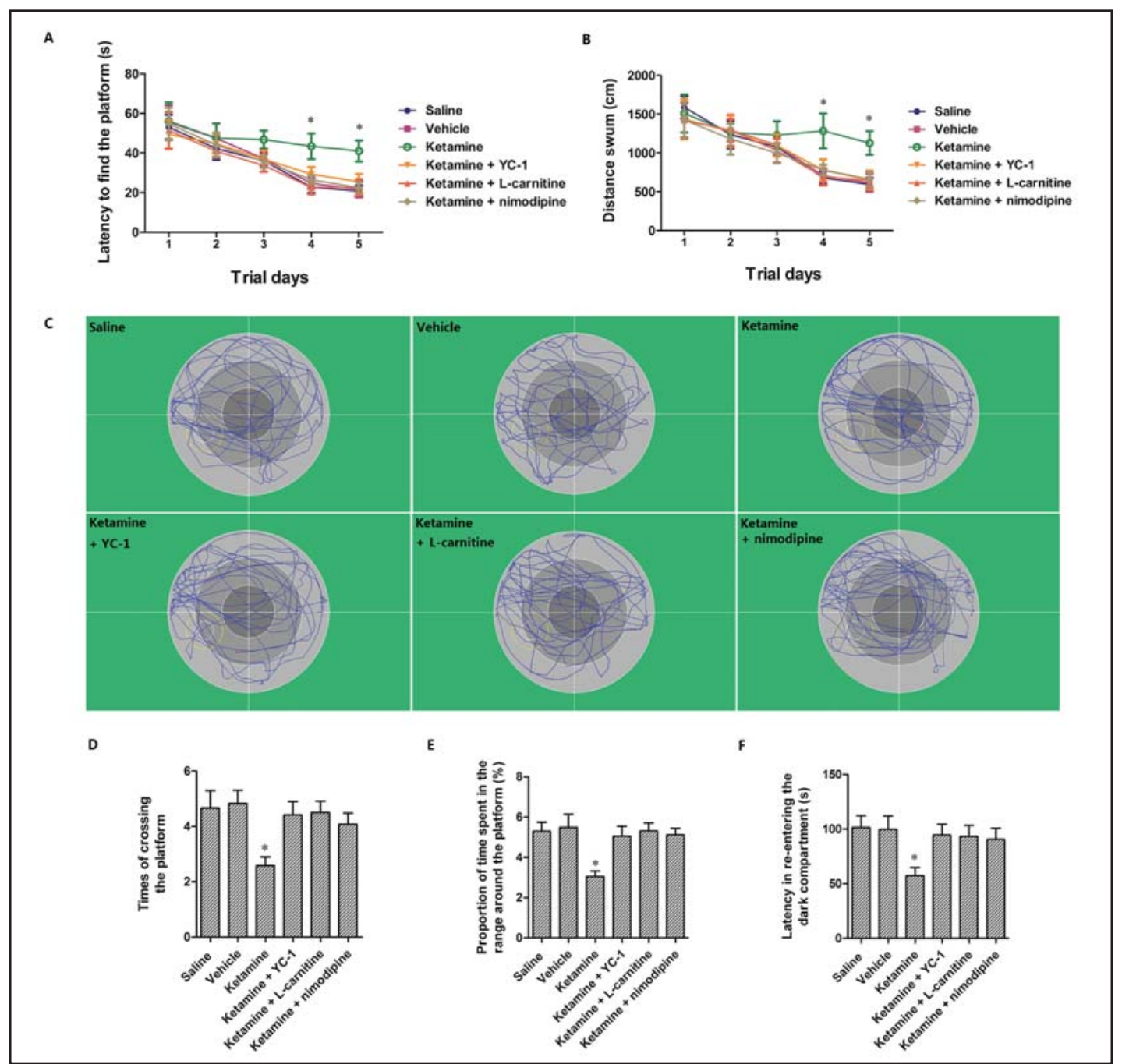

Fig. 8. Behavioral tests for the evaluation of learning and memory. P7 rat pups were divided into six groups according to different drug treatments (saline, vehicle, ketamine, ketamine+YC-1, ketamine+L-carnitine, ketamine+nimodipine) by i.p. injection, once per day for 3 consecutive days. When the rats grew, the Morris water maze test (P42 rats) and passive avoidance test (P60 rats) were performed. (A-E) Quantification and analysis of parameters measured in the Morris water maze test, comparing animals from all six groups. A \& B show the results of the training trials. C-E show the results of the spatial probe trials. (A) Latency in finding the hidden platform (Trial day 1: $\mathrm{F}[5,66]=0.10, P=0.9918$; Trial day 2: $\mathrm{F}[5,66]=0.21, P=0.9579$; Trial day 3: $\mathrm{F}[5,66]=1.56, P=0.1836$; Trial day 4: $\mathrm{F}[5,66]=4.22, P=0.0022$; Trial day 5: $\mathrm{F}[5,66]=3.77, P=0.0046)$. (B) Distance swum before finding the platform (Trial day 1 : $\mathrm{F}[5,66]=0.09, P=0.9934$; Trial day 2: $\mathrm{F}[5,66]=0.06$, $P=0.9978$; Trial day 3: $\mathrm{F}[5,66]=0.33, P=0.8920$; Trial day 4: $\mathrm{F}[5,66]=3.20, P=0.0119$; Trial day $5: \mathrm{F}[5,66]=3.26$, $P=0.0109$ ). (C) Representative traces of the paths swum by the animals in the spatial probe trial. The white circle represents the removed platform. The yellow circle represents the range around the platform $(200 \%$ of the platform's area as set by the software). (D) Number of times the platform was crossed $(F[5,66]=3.15$, $P=0.0131)$. (E) Proportion of time spent in the range around the platform $(\mathrm{F}[5,66]=4.00, P=0.0031)$. (F) Passive avoidance test $(\mathrm{F}[5,66]=2.53, P=0.0371) .{ }^{*} P<0.05$ for the ketamine group versus any of the other groups.

the expression of HIF- $1 \alpha$ at the mRNA level in all six treatment groups, using RT-PCR. As shown, both in vitro as well as in vivo, the upregulation of HIF-1 $\alpha$ mRNA in samples exposed repeatedly to ketamine was rescued significantly when the cells were also treated with L-carnitine or nimodipine (Fig. 7). However, when primary neurons were co-treated with 


\section{Cellular Physiology and Biochemistry}

Cell Physiol Biochem 2014;33:1715-1732

DOI: 10.1159/000362953

Publisned onIIne: IVlay 20, 2014

Yan et al.: Ketamine and HIF-1 $\alpha$
(C) 2014 S. Karger AG, Basel

www.karger.com/cpb

ketamine and YC-1, the latter had no effect on HIF-1 $\alpha$ mRNA expression. Hence, in the ketamine+YC-1 group, the upregulation in HIF-1 $\alpha$ expression was comparable to that in the ketamine only group and significantly higher than in the control group, both in vitro and in vivo (Fig. 7). This finding suggests that YC-1 could regulate HIF- $1 \alpha$ activity only at the posttranscriptional level.

Ketamine-induced defects in learning and memory could be rescued by YC-1, L-carnitine and nimodipine

Several studies have shown that repeated exposure to ketamine during development can result in cognitive deficiencies during later stages $[3,46]$. To determine whether our rat model of ketamine overexposure displayed the same long-term defects, we performed two behavioral tests on older animals (P42 and P60) to evaluate their learning and memory skills. First, we subjected 12 P42 animals from each group to the Morris water maze test. Our assay showed that on days 4 and 5 of the trial, the latency and the distance swum were increased significantly in ketamine-exposed rats (Fig. 8A \& B). However, those animals that were administered YC-1, L-carnitine or nimodipine following ketamine did not display any differences in any of these parameters, compared to the control group (Fig. 8A \& B). Moreover, the numbers of times the rats crossed the platform and the proportion of time spent in the range around the platform decreased significantly with ketamine-exposere (Fig. 8D \& E). Representative traces of the movement of the animals in the spatial probe test at the end of the training period from all six groups was also shown in all six group, with the platform encircled in white and the range around the platform marked in yellow (Fig. 8C). To corroborate these findings, we next performed a second behavioral assay, the passive avoidance test, and we measured the time taken by the animals to re-enter the dark compartment (latency), thus evaluating their ability to remember the electric foot shock delivered in preceding trials (Fig. 8F). As expected from the results above, ketamine-exposed animals displayed less latency and were quicker to re-enter the dark compartment. This finding reflected a deficiency in their ability to learn and remember. Again, this effect could be rescued by treatment with YC-1, L-carnitine or nimodipine (Fig. 8F).

\section{Discussion}

Significant safety concerns regarding the use of anesthesia during early development have arisen since the first nonclinical report indicating that administration of NMDA receptor antagonists during the early stages of CNS development could produce neurotoxicity [1]. The brain is most vulnerable to neurotoxic agents during the "brain's growth spurt" (BGS), which begins at mid-gestation and continues for 2-3 years after birth in humans and which occurs during the first 2-3 weeks after birth in rodents [47]. This timing is an important consideration because a series of animal experiments suggested that general anesthetics could trigger apoptosis in the developing brain [47]. Ketamine is an NMDA receptor antagonist that is widely used in pediatric anesthesia, and sub-anesthetic doses of ketamine are frequently used for perioperative sedation, analgesia, and other diagnostic procedures in pediatric patients. It is also known that ketamine can cause neuronal apoptosis in the developing mammalian brain $[2-8,13,14]$ and, consequently, long-term defects in learning and memory $[3,46]$. When immature neurons are exposed to blockers of NMDA receptors, these cells activate a compensatory mechanism following withdrawal that causes increased expression of NMDA receptors, leading to increased sensitivity to extracellular glutamate. The resulting enhancement of the activation of the NMDA receptors causes excitotoxicity and an increase in calcium influx $[11,12]$. Because calcium is an important secondary messenger, a disturbance in its homeostasis leads to aberrant activation of downstream molecular pathways, including excessive mitochondrial ROS generation, which can activate apoptotic pathways [4, 6, 8-14]. However, the downstream molecular signals leading from excessive mitochondrial ROS generation to ketamine-induced apoptosis are not well understood. 


\section{Cellular Physiology and Biochemistry}

Cell Physiol Biochem 2014;33:1715-1732

DOI: $10.1159 / 000362953$

Published onlıne: Mlay 20, 2014

C) 2014 S. Karger AG, Basel

www.karger.com/cpb

In this study, we investigated the molecular mechanism of the upregulation of ROS in developing hippocampal neurons exposed repetitively to ketamine. First, we established that in both our in vitro and in vivo models of developmental ketamine-exposure, there was indeed significantly greater apoptosis of hippocampal neurons, together with upregulation of pro-apoptotic (p53, BNIP3, Bax) and downregulation of anti-apoptotic (Bcl-2) effectors. This finding was in accordance with findings previously reporting that NMDA receptor antagonists could cause excitotoxicity, which could in turn activate pro-apoptotic signaling. Next, we investigated the molecular link between ketamine-induced excitotoxicity and proapoptotic signaling. It is generally accepted that cell hypoxia can cause overexpression of HIF- $1 \alpha$. Several studies have provided evidence that HIF- $1 \alpha$ activity is enhanced following hypoxic insult and traumatic brain injury $[22,23]$. In these conditions, HIF- $1 \alpha$ plays a neuroprotective, pro-survival role by activating downstream genes, such as vascular endothelial growth factor (VEGF), erythropoietin (EPO) and glucose transporter (Glut1), to promote angiogenesis. Other studies have shown that when activated, depending on the length of the insult and the type of stimulus, HIF- $1 \alpha$ can have both neuroprotective and neurodegenerative function $[19,44,45,48,49]$. This dual function has also been observed in neurons responding to the anesthetic isoflurane $[15,20]$. It is also known that HIF-1 $\alpha$ activation is associated with upregulation of reactive oxygen species in response to stress factors, such as excitotoxicity and increased calcium influx, under normoxic conditions $[21,43]$. Based on these findings, we hypothesized that the upregulation of pro-apoptotic signaling, in both our in vitro and in vivo models of developmental ketamine exposure, might be associated with increases in HIF- $1 \alpha$ activity and ROS concentrations in the cells. Through multiple molecular assays, we proved this hypothesis to be possible in both of our models.

Several studies have identified small molecules, including lithium, NOS inhibitors and CDK5 inhibitors, that could protect against the neuroapoptosis induced by anesthetics such as ketamine and isoflurane [50-52]. The $\mathrm{Ca}^{2+}$ channel blockers nimodipine and nifedipine have also been shown to exert neuroprotective effects [33,34]. In this study, we tested three neuroprotective molecules - the $\mathrm{Ca}^{2+}$ channel blocker nimodipine, L-carnitine, and the HIF-1 $\alpha$ inhibitor YC-1, and we showed that they could reverse pro-apoptotic signaling and neuronal cell death both in vitro and in vivo. However, only L-carnitine and nimodipine could prevent the upregulation of ROS in ketamine-exposed neurons. L-carnitine is an antioxidant that can control the excessive production of ROS and that was shown to protect against neuronal apoptosis [10]. Based on evidence that excessive ROS could activate HIF- $1 \alpha$ and that severe HIF- $1 \alpha$ activation could induce neuronal apoptosis [21, 43-45, 49, 53], our finding suggests that ketamine-induced neurodegeneration was mediated by the upregulation of ROS, which in turn caused upregulation of HIF- $1 \alpha$. When excessive generation of ROS in ketamine-exposed hippocampal neurons was neutralized by L-carnitine, HIF- $1 \alpha$ activity, and therefore the percentage of apoptotic neurons, was comparable to control levels. In contrast, nimodipine is a $\mathrm{Ca}^{2+}$ channel blocker. As mentioned earlier, it has been well established that ketamine can induce excitotoxicity due to excessive calcium influx and activation of apoptotic pathways $[11,12]$. Therefore, we did not repeat the intracellular calcium concentration evaluation after ketamine administration. In this study, treatment with nimodipine most likely prevented the elevation in intracellular calcium levels, leading to depression of apoptotic pathways and restoration of neuronal cell death to control levels. Our findings demonstrated indirectly that ketamine-induced apoptosis was mediated via upregulation of intracellular calcium, most likely in response to the former's antagonistic activity on NMDA receptors.

The HIF-1 $\alpha$ inhibitor YC-1 successfully prevented the upregulation of the proapoptotic effectors p53, BNIP3, Bax, and cleaved caspase-3 enzyme and HIF-1 $\alpha$ protein, the downregulation of anti-apoptotic Bcl-2, and neuronal cell death in ketamine-exposed immature hippocampal neurons both in vitro and in vivo. However, YC-1 failed to downregulate ROS levels or HIF-1 $\alpha$ mRNA expression in these neurons. Our observations suggest that in addition to intracellular $\mathrm{Ca}^{2+}$ and ROS, apoptosis of ketamine-exposed neurons was also 


\section{Cellular Physiology and Biochemistry}

Cell Physiol Biochem 2014;33:1715-1732

\begin{tabular}{l|l}
\hline DOI: $10.1159 / 000362953$ & C 2014 S. Karger AG, Basel
\end{tabular}

www.karger.com/cpb

mediated by the upregulation of HIF- $1 \alpha$ and activation of downstream genes, such as BNIP3 and p53, in accordance with previous reports $[45,49]$. Hence, when treated with YC-1, neuronal cell death and activation of apoptotic signaling were rescued both in vitro and in vivo. Because HIF- $1 \alpha$ is not known to have a direct influence on ROS generation, YC-1 had no effect on this phenotype in ketamine-exposed neurons. However, based on the finding that YC-1 did rescue the neurons from apoptosis, HIF- $1 \alpha$ is most likely to act downstream of ROS in the pathway leading from ketamine to cell death. Our observations on HIF-1 $\alpha$ expression (at the mRNA level) suggest that YC-1 clearly had no influence on HIF-1 $\alpha$ expression. However, it could successfully downregulate the HIF- $1 \alpha$ protein to control levels, as seen from our western blot experiments. This finding suggests that YC-1 could inhibit HIF-1 $\alpha$ activity at the protein level, but not at the mRNA level, in accordance with previous reports [18, 31, 32, 54]. Because the increase in HIF-1 $\alpha$ expression could be rescued by L-carnitine and nimodipine, we hypothesize that the elevation in intracellular $\mathrm{Ca}^{2+}$ and ROS induced the increase in HIF$1 \alpha$ mRNA levels in ketamine-exposed neurons.

Finally, our studies conclusively demonstrate that ketamine-induced apoptosis of developing hippocampal neurons led to significant long-term defects in cognitive abilities, including learning and memory, in older animals, in accordance with previous reports $[3,46]$. We showed that the small molecules that could rescue the cellular and molecular phenotype of developmental ketamine exposure could also rescue the physiological and behavioral phenotype in older rats. All three neuroprotective factors - YC-1, L-carnitine and nimodipine - successfully prevented learning and memory deficiencies in rats exposed to ketamine during early postnatal development. To understand better the deleterious effects of anesthetics such as ketamine on brain development, further studies are needed to elucidate the molecular links between HIF-1 $\alpha$ upregulation and the activation of proapoptotic pathways in developing neurons.

In conclusion, our study successfully dissected the molecular pathway leading from repeated ketamine administration during development to learning and memory deficits in older animals. Using both in vitro and in vivo models, we showed that developmental ketamine-exposure led to upregulation of ROS, which caused increased expression of HIF- $1 \alpha$, which then activated downstream pathways, causing upregulation of p53, BNIP3, and Bax and downregulation of factor Bcl-2. This alteration in the ratio of pro-apoptotic to pro-survival signaling led to increased caspase- 3 activity, elevation in the apoptosis of hippocampal neurons, and significant deficiencies in learning and memory at later stages. We also showed that ketamine-induced neurodegeneration and long-term cognitive defects could be prevented by treatment with the HIF-1 $\alpha$ inhibitor YC-1, the antioxidant L-carnitine and the $\mathrm{Ca}^{2+}$ channel blocker nimodipine. To our knowledge, this was the first report elucidating the molecular pathway underlying ketamine-induced increases in ROS production, which are responsible for developmental neurodegeneration. Our study contributes to the growing evidence of the detrimental effects of certain anesthetics, and it strongly suggests that precautions should be undertaken when using these drugs in pediatric surgeries.

\section{Disclosure Statement}

The authors do not have conflict of interest to declare for this work.

\section{Acknowledgements}

This work was supported by research funds from Shanghai Ninth People's Hospital Affiliated to Shanghai Jiao Tong University School of Medicine [grant number: 2012A04] and Shanghai Society of Anesthesiology (to Dr. Jia Yan). 


\section{Cellular Physiology \\ and Biochemistry}

Cell Physiol Biochem 2014;33:1715-1732

\begin{tabular}{l|l}
\hline DOI: $10.1159 / 000362953$ & (C) 2014 S. Karger AG, Basel
\end{tabular}

www.karger.com/cpb

Yan et al.: Ketamine and HIF- $1 \alpha$

\section{References}

1 Ikonomidou C, Bosch F, Miksa M, Bittigau P, Vöckler J, Dikranian K, Tenkova TI, Stefovska V, Turski L, Olney JW: Blockade of NMDA receptors and apoptotic neurodegeneration in the developing brain. Science 1999;283:70-74.

-2 Hayashi H, Dikkes P, Soriano SG: Repeated administration of ketamine may lead to neuronal degeneration in the developing rat brain. Paediatr Anaesth 2002;12:770-774.

3 Huang L, Liu Y, Jin W, Ji X, Dong Z: Ketamine potentiates hippocampal neurodegeneration and persistent learning and memory impairment through the PKC $\gamma$-ERK signaling pathway in the developing brain. Brain Res 2012;1476:164-171.

4 Liu F, Paule MG, Ali S, Wang C: Ketamine-induced neurotoxicity and changes in gene expression in the developing rat brain. Curr Neuropharmacol 2011;9:256-261.

-5 Scallet AC, Schmued LC, Slikker W Jr, Grunberg N, Faustino PJ, Davis H, Lester D, Pine PS, Sistare F, Hanig JP: Developmental neurotoxicity of ketamine: morphometric confirmation, exposure parameters, and multiple fluorescent labeling of apoptotic neurons. Toxicol Sci 2004;81:364-370.

6 Shi Q Guo L, Patterson TA, Dial S, Li Q, Sadovova N, Zhang X, Hanig JP, Paule MG, Slikker W Jr, Wang C: Gene expression profiling in the developing rat brain exposed to ketamine. Neuroscience 2010;166:852-863.

7 Soriano SG, Liu Q Li J, Liu J-R, Han XH, Kanter JL, Bajic D, Ibla JC: Ketamine activates cell cycle signaling and apoptosis in the neonatal rat brain. Anesthesiology 2010;112:1155-1163.

-8 Zou X, Patterson TA, Sadovova N, Twaddle NC, Doerge DR, Zhang X, Fu X, Hanig JP, Paule MG, Slikker W, Wang C: Potential neurotoxicity of ketamine in the developing rat brain. Toxicol Sci 2009;108:149-158.

9 Wang C, Slikker W Jr: Strategies and experimental models for evaluating anesthetics: effects on the developing nervous system. Anesth Analg 2008;106:1643-1658.

- 10 Liu F, Patterson TA, Sadovova N, Zhang X, Liu S, Zou X, Hanig JP, Paule MG, Slikker W Jr, Wang C: KetamineInduced Neuronal Damage and Altered N-methyl-D-aspartate (NMDA) Receptor Function in Rat Primary Forebrain Culture. Toxicol Sci 2013;131:548-557.

11 Slikker W Jr, Paule MG, Wright LK, Patterson TA, Wang C: Systems biology approaches for toxicology. J Appl Toxicol 2007;27:201-217.

12 Slikker W, Xu Z, Wang C: Application of a systems biology approach to developmental neurotoxicology. Reprod Toxicol 2005;19:305-319.

13 Slikker W Jr, Zou X, Hotchkiss CE, Divine RL, Sadovova N, Twaddle NC, Doerge DR, Scallet AC, Patterson TA, Hanig JP, Paule MG, Wang C: Ketamine-induced neuronal cell death in the perinatal rhesus monkey. Toxicol Sci 2007;98:145-158.

14 Ullah N, Ullah I, Lee HY, Naseer MI, Seok PM, Ahmed J, Kim MO: Protective function of nicotinamide against ketamine-induced apoptotic neurodegeneration in the infant rat brain. J Mol Neurosci 2012;47:67-75.

-15 Jiang H, Huang Y, Xu H, Sun Y, Han N, Li QF: Hypoxia inducible factor- $1 \alpha$ is involved in the neurodegeneration induced by isoflurane in the brain of neonatal rats. J Neurochem 2012;120:453-460.

-16 Huang LE, Gu J, Schau M, Bunn HF: Regulation of hypoxia-inducible factor 1alpha is mediated by an 02-dependent degradation domain via the ubiquitin-proteasome pathway. Proc Natl Acad Sci USA 1998;95:7987-7992.

17 Kenneth NS, Rocha S: Regulation of gene expression by hypoxia. Biochem J 2008;414:19-29.

18 Jiang H, Huang Y, Xu H, Hu R, Li Q-F: Inhibition of hypoxia inducible factor-1 $\alpha$ ameliorates lung injury induced by trauma and hemorrhagic shock in rats. Acta Pharmacol Sin 2012;33:635-643.

19 Chen W, Ostrowski RP, Obenaus A, Zhang JH: Prodeath or prosurvival: two facets of hypoxia inducible factor-1 in perinatal brain injury. Exp Neurol 2009;216:7-15.

20 Li QF, Zhu YS, Jiang H: Isoflurane preconditioning activates HIF-1alpha, iNOS and Erk1/2 and protects against oxygen-glucose deprivation neuronal injury. Brain Res 2008;1245:26-35.

21 Kietzmann T, Görlach A: Reactive oxygen species in the control of hypoxia-inducible factor-mediated gene expression. Semin Cell Dev Biol 2005;16:474-486.

-22 Dong Y, Li Y, Feng D, Wang J, Wen H, Liu D, Zhao D, Liu H, Gao G, Yin Z, Qin H: Protective effect of HIF-1 $\alpha$ against hippocampal apoptosis and cognitive dysfunction in an experimental rat model of subarachnoid hemorrhage. Brain Res 2013;1517:114-121.

23 Yan J, Zhou B, Taheri S, Shi H: Differential effects of HIF-1 inhibition by YC-1 on the overall outcome and blood-brain barrier damage in a rat model of ischemic stroke. PLoS One 2011;6:e27798. 


\section{Cellular Physiology and Biochemistry}

Cell Physiol Biochem 2014;33:1715-1732

\begin{tabular}{l|l}
\hline DOI: $10.1159 / 000362953$ & (C) 2014 S. Karger AG, Basel
\end{tabular}

Yan et al.: Ketamine and HIF- $1 \alpha$

24 Wei H, Kang B, Wei W, Liang G, Meng QC, Li Y, Eckenhoff RG: Isoflurane and sevoflurane affect cell survival and BCL-2/BAX ratio differently. Brain Res 2005;1037:139-147.

25 Moosavi M, Maghsoudi N, Zahedi-Asl S, Naghdi N, Yousefpour M, Trounce IA: The role of PI3/Akt pathway in the protective effect of insulin against corticosterone cell death induction in hippocampal cell culture. Neuroendocrinology 2008;88:293-298.

26 Guo ZY, Li CZ, Li XJ, Wang YL, Mattson MP, Lu CB: The developmental regulation of glutamate receptormediated calcium signaling in primary cultured rat hippocampal neurons. NeuroReport 2013;24:492-497.

-27 Wang C, Sadovova N, Fu X, Schmued L, Scallet A, Hanig J, Slikker W: The role of the N-methyl-D-aspartate receptor in ketamine-induced apoptosis in rat forebrain culture. Neuroscience 2005;132:967-977.

28 Wang C, Kaufmann JA, Sanchez-Ross MG, Johnson KM: Mechanisms of N-methyl-D-aspartate-induced apoptosis in phencyclidine-treated cultured forebrain neurons. J Pharmacol Exp Ther 2000;294:287-295

29 Takadera T, Ishida A, Ohyashiki T: Ketamine-induced apoptosis in cultured rat cortical neurons. Toxicol Appl Pharmacol 2006;210:100-107.

-30 Wang S-Q, Li X-J, Zhou S, Sun D-X, Wang H, Cheng PF, Ma XR, Liu L, Liu JX, Wang FF, Liang YF, Wu JM: Intervention Effects of Ganoderma Lucidum Spores on Epileptiform Discharge Hippocampal Neurons and Expression of Neurotrophin-4 and N-Cadherin. PLoS ONE 2013;8:e61687.

-31 Sun H-L, Liu Y-N, Huang Y-T, Pan S-L, Huang D-Y, Guh JH, Lee FY, Kuo SC, Teng CM: YC-1 inhibits HIF-1 expression in prostate cancer cells: contribution of Akt/NF-jB signaling to HIF-1a accumulation during hypoxia. Oncogene 2007;26:3941-3951.

-32 Zhao Q Du J, Gu H, Teng X, Zhang Q Qin H, Liu N: Effects of YC-1 on hypoxia-inducible factor 1-driven transcription activity, cell proliferative vitality, and apoptosis in hypoxic human pancreatic cancer cells. Pancreas 2007;34:242-247.

- 33 Ferenz KB, Gast RE, Rose K, Finger IE, Hasche A, Krieglstein J: Nerve growth factor and brain-derived neurotrophic factor but not granulocyte colony-stimulating factor, nimodipine and dizocilpine, require ATP for neuroprotective activity after oxygen-glucose deprivation of primary neurons. Brain Res 2012;1448:20-26.

-34 Lecht S, Rotfeld E, Arien-Zakay H, Tabakman R, Matzner H, Yaka R, Lelkes PI, Lazarovici P: Neuroprotective effects of nimodipine and nifedipine in the NGF-differentiated PC12 cells exposed to oxygen-glucose deprivation or trophic withdrawal. Int J Devl Neurosci 2012;30:465-469.

-35 Liu JR, Liu Q, Li J, Baek C, Han XH, Athiraman U, Soriano SG: Noxious stimulation attenuates ketamineinduced neuroapoptosis in the developing rat brain. Anesthesiology 2012;117:64-71.

36 Zou X, Sadovova N, Patterson TA, Divine RL, Hotchkiss CE, Ali SF, Hanig JP, Paule MG, Slikker W Jr, Wang C: The effects of l-carnitine on the combination of, inhalation anesthetic-induced developmental, neuronal apoptosis in the rat frontal cortex. Neuroscience 2008;151:1053-1065.

-37 Zhu C, Gao J, Karlsson N, Li Q, Zhang Y, Huang Z, Li H, Kuhn HG, Blomgren K: Isoflurane anesthesia induced persistent, progressive memory impairment, caused a loss of neural stem cells, and reduced neurogenesis in young, but not adult, rodents. J Cereb Blood Flow Metab 2010;30:1017-1030.

- 38 Yon J-H, Daniel-johnson J, Carter LB, Jevtovic-Todorovic V: Anesthesia induces neuronal cell death in the developing rat brain via the intrinsic and extrinsic apoptotic pathways. Neuroscience 2005;135:815-827.

- 39 Jevtovic-Todorovic V, Hartman RE, Izumi Y, Benshoff ND, Dikranian K, Zorumski CF, Olney JW, Wozniak DF: Early exposure to common anesthetic agents causes widespread neurodegeneration in the developing rat brain and persistent learning deficits. J Neurosci 2003;23:876-882.

-40 Salma J, McDermott JC: Suppression of a MEF2-KLF6 survival pathway by PKA signaling promotes apoptosis in embryonic hippocampal neurons. J Neurosci 2012;32:2790-2803.

41 Shu Y, Zhou Z, Wan Y, Sanders RD, Li M, Pac-Soo CK, Maze M, Ma D: Nociceptive stimuli enhance anestheticinduced neuroapoptosis in the rat developing brain. Neurobiol Dis 2012;45:743-750.

42 Ozarowski M, Mikolajczak PL, Bogacz A, Gryszczynska A, Kujawska M, Jodynis-Liebert J, Piasecka A, Napieczynska H, Szulc M, Kujawski R, Bartkowiak-Wieczorek J, Cichocka J, Bobkiewicz-Kozlowska T, Czerny B, Mrozikiewicz PM: Rosmarinus officinalis L. leaf extract improves memory impairment and affects acetylcholinesterase and butyrylcholinesterase activities in rat brain. Fitoterapia 2013;91:261-271.

43 Bonello S, Zähringer C, BelAiba RS, Djordjevic T, Hess J, Michiels C, Kietzmann T, Görlach A.: Reactive oxygen species activate the HIF-1 $\alpha$ promoter via a functional NF B site. Arterioscler Thromb Vasc Biol 2007;27:755-761. 


\section{Cellular Physiology \\ Cell Physiol Biochem 2014;33:1715-1732 and Biochemistry

Yan et al.: Ketamine and HIF-1 $\alpha$

44 Bruick RK: Expression of the gene encoding the proapoptotic Nip3 protein is induced by hypoxia. Proc Natl Acad Sci USA 2000;97:9082-9087.

-45 Halterman MW, Miller CC, Federoff HJ: Hypoxia-inducible factor-1a mediates hypoxia-induced delayed neuronal death that involves p53. J Neurosci 1999;19:6818-6824.

46 Fredriksson A, Archer T, Alm H, Gordh T, Eriksson P: Neurofunctional deficits and potentiated apoptosis by neonatal NMDA antagonist administration. Behav Brain Res 2004;153:367-376.

47 Yan J, Jiang H: Dual Effects of Ketamine: Neurotoxicity Versus Neuroprotection in Anesthesia for the Developing Brain. J Neurosurg Anesthesiol 2014;26:155-160.

-48 Aminova LR, Chavez JC, Lee J, Ryu H, Kung A, Lamanna JC, Ratan RR: Prosurvival and prodeath effects of hypoxia-inducible factor- $1 \alpha$ stabilization in a murine hippocampal cell line. J Biol Chem 2005;280:39964003.

49 Althaus J, Bernaudin M, Petit E, Toutain J, Touzani O, Rami A: Expression of the gene encoding the proapoptotic BNIP3 protein and stimulation of hypoxia-inducible factor-1a (HIF-1a) protein following focal cerebral ischemia in rats. Neurochem Int 2006;48:687-695.

-50 Straiko MMW, Young C, Cattano D, Creeley CE, Wang H, Smith DJ, Johnson SA, Li ES, Olney JW: Lithium protects against anesthesia-induced developmental neuroapoptosis. Anesthesiology 2009;110:862-868.

-51 Wang C, Sadovova N, Patterson TA, Zou X, Fu X, Hanig JP, Paule MG, Ali SF, Zhang X, Slikker W Jr: Protective effects of 7-nitroindazole on ketamine-induced neurotoxicity in rat forebrain culture. Neurotoxicology 2008;29:613-620.

-52 Wang W-Y, Luo Y, Jia L-J, Hu S-F, Lou X-K, Lu H, Zhang HH, Yang R, Wang H, Ma ZW, Xue QS, Yu BW: Inhibition of aberrant cyclin-dependent kinase 5 activity attenuates isoflurane neurotoxicity in the developing brain. Neuropharmacology 2014;77:90-99.

53 Li A, Sun X, Ni Y, Chen X, Guo A: HIF-1 $\alpha$ involves in neuronal apoptosis after traumatic brain injury in adult rats. J Mol Neurosci 2013;51:1052-1062.

-54 Kim HL, Yeo EJ, Chun YS, Park JW: A domain responsible for HIF- 1alpha degradation by YC-1, a novel anticancer agent. Int J Oncol 2006;29:255-260. 